\title{
Influence of prebiotics and antioxidants in bread on the immune system, antioxidative status and antioxidative capacity in male smokers and non-smokers
}

\author{
Christiane Seidel ${ }^{1}$, Volker Boehm ${ }^{1}$, Heinz Vogelsang ${ }^{2}$, Andreas Wagner ${ }^{1}$, Christoph Persin ${ }^{3}$, \\ Michael Glei ${ }^{1}$, Beatrice L. Pool-Zobel ${ }^{1}$ and Gerhard Jahreis ${ }^{1 *}$ \\ ${ }^{1}$ Friedrich Schiller University, Institute of Nutrition, Dornburger Strasse 24-29, D-07743 Jena, Germany \\ ${ }^{2}$ Friedrich Schiller University, Institute of Clinical Medicine and Laboratory Diagnostics, Jena, Germany \\ ${ }^{3}$ Kampffmeyer Food Service GmbH, Hamburg, Germany
}

(Received 28 April 2006 - Revised 26 September 2006 - Accepted 26 September 2006)

\begin{abstract}
Interest in functional foods is increasing. The aim of the present study was to investigate breads supplemented with functional components. One was bread supplemented with inulin, linseed and soya fibre (prebiotic bread). The other was a prebiotic antioxidant bread (pre-aox-bread), which additionally contained green tea powder, herbs and tomato paste. The effects of these two breads on immunological and antioxidative parameters were compared with control bread (placebo). Twenty smokers and eighteen non-smokers were enrolled in the randomised parallel study, which consisted of a control period and an intervention period, each lasting for 5 weeks. Daily intake of bread and nutrients did not differ between the intervention and the control period. Most of the twenty-three investigated immunological parameters measured in peripheral blood were unaffected. However, the percentage of CD19 increased after intervention with prebiotic bread, whereas intercellular adhesion molecule-1 (ICAM-1) and CD3 $+\mathrm{NK}+(P<0 \cdot 05)$ decreased in both intervention arms. The ferric reducing ability of plasma (FRAP) was increased after consumption of the pre-aox-bread for non-smokers (1256 v. $1147 \mu \mathrm{mol} / 1 ; P=0.019)$ and remained unchanged for smokers consuming the preaox-bread. All analysed carotenoids $(P \leq 0.001)$ in plasma were increased after the consumption of pre-aox-bread. The concentrations of uric acid and $\alpha$-tocopherol rose after intervention with both breads. ICAM-1 as a marker of stress decreased after consuming the prebiotic bread. In conclusion, increased plasma concentrations of carotenoids and the responses observed with the FRAP assay after intervention with the preaox-bread indicate a unique response in terms of antioxidative potentials for this type of functional food.
\end{abstract}

Prebiotics: Green tea: Tomato paste: Antioxidant capacity: Smokers

The concept of 'functional foods' was pioneered in Japan during the 1980s (Arai, 1996). Functional foods 'should either have a relevant effect on well-being and health or result in a reduced risk of disease' (Roberfroid, 1999). Due to changes in attitudes towards nutrition together with advances in technology in the last two decades, functional foods are generating considerable interest in consumers and researchers alike.

Prebiotics fulfil the criteria of being functional food ingredients due to their effects in both animals and human consumers. Research on inulin and oligofructose has revealed a beneficial influence of these food ingredients on faecal weight and faecal transit time (Alles et al. 1996; Gibson et al. 1999), the mineral absorption (Coudray et al. 1997; van den Heuvel et al. 1998, 1999; van Loo et al. 1999; Griffin et al. 2002), the risk of colon cancer (Reddy, 1999; Buddington et al. 2002; Pool-Zobel et al. 2002), the immune system (Schley \& Field, 2002; Kelly-Quagliana et al. 2003) and lastly on concentration of blood lipids (Anderson \& Hanna, 1999; Brighenti et al. 1999; Causey et al. 2000; Letexier et al. 2003).
Health benefits have also been attributed to antioxidants, including a reduced risk of CVD (Weisburger, 1998; Connor et al. 2004; Rajasekhar et al. 2004; Sano et al. 2004), and some forms of cancer (Weisburger, 1998; Cooper et al. 1999; Lee et al. 2004; Jian et al. 2005; Weinstein et al. 2005). In their aetiology, these chronic diseases seem to result from cellular oxidative damage, caused by pro-oxidative agents, such as free radicals affecting lipids, proteins and DNA (Nikoleit, 1997). Dietary antioxidants may protect against these oxidative events in the body in cases where insufficient levels of endogenous antioxidants cannot counteract the reactive species (Rietveld \& Wiseman, 2003). Moreover, since the antioxidative activity of flavonoids and carotenoids is assumed to be dose-dependent (Upritchard et al. 2003), an enhanced uptake of these nutritional components within functional foods is considered to be of added value.

Tea (Camellia sinensis) and its catechin ingredients have strong antioxidant properties (Trevisanato \& Kim, 2000; Peters et al. 2001; McKay \& Blumberg, 2002; Rietveld \&

\footnotetext{
Abbreviations: FRAP, ferric reducing ability of plasma; GAE, gallic acid equivalent; ICAM-1, intercellular adhesion molecule-1; PCL, photosensitive chemoluminescence; pre-aox-bread, prebiotic antioxidant bread; TRAP, total radical-trapping antioxidant parameter.

* Corresponding author: Dr Gerhard Jahreis, fax +49 3641 949612, email Gerhard.Jahreis@uni-jena.de
} 
Wiseman, 2003), protecting human cells from DNA damage (Glei et al. 2005). Carotenoids, also presumed to have antioxidant capacity, may promote cell-cell communication and influence the immune response (Nikoleit, 1997; Murr et al. 2005). Although the association between carotenoids and CVD or cancer is to date controversial, many studies suggest a health benefit due to these types of phytochemicals, in particular, carotenoids (Hertog et al. 1993; Weisburger, 1998; Cooper et al. 1999; Riley \& Stouffer, 2003; Schabath et al. 2004; Nkondjock et al. 2005).

The aim of the present study was to assess the effects of prebiotics and antioxidants incorporated into a food consumed on a daily basis. We determined whether dietary intervention with supplemented breads affects the antioxidative capacity in plasma and immunological parameters in blood.

\section{Subjects and methods}

\section{Subjects}

Volunteers were recruited via newspaper advertisements. Criteria of exclusion were gastrointestinal disease and diabetes. All volunteers gave their informed written consent. The study was approved by the ethical committee of the Friedrich Schiller University (Jena, Germany).

Twenty current male smokers (smoking five or more cigarettes per d) and eighteen male non-smokers with a BMI of $23.2 \mathrm{~kg} / \mathrm{m}^{2}$ were enrolled in the study (Table 1 ). The thirtyeight men were equally distributed into four groups regarding their smoking status and type of intervention bread (prebiotic bread or prebiotic antioxidant bread (pre-aox-bread)).

All parameters listed in Table 1 (body composition, dietary intakes, blood lipids) did not differ within the subgroups smokers $v$. non-smokers and within subjects consuming the prebiotic bread $v$. subjects consuming the pre-aox-bread.

\section{Experimental design}

The randomised, parallel, double-blind study consisted of two experimental periods. The trial was conducted for 12 weeks, starting with a baseline period of 2 weeks in which the volunteers were asked to follow their normal diet and to complete a $7 \mathrm{~d}$ dietary record. This period was followed by the control period (placebo) and, subsequently, the intervention period, both lasting 5 weeks. All thirty-eight volunteers were asked to eat the placebo bread during the control period. During the intervention period, nineteen subjects consumed the prebiotic bread and the rest ate the pre-aox-bread. Participants were instructed to consume at least $200 \mathrm{~g}$ bread per day during both periods. In the last $7 \mathrm{~d}$ of both parts of the study, the volunteers were given a standardised diet. The subjects collected $24 \mathrm{~h}$ urine samples for $3 \mathrm{~d}$ and faeces for $5 \mathrm{~d}$ at the end of all periods. On the last day of all phases, blood was collected after overnight fasting and the body composition of the subjects was analysed using bioelectric impedance analysis.

\section{Test breads and standardised diets}

The bread provided in the control period was a common German wheat-rye bread (Table 2). The prebiotic bread contained inulin, soya and linseed; the pre-aox-bread was prepared by adding tomato paste, green tea powder and oregano as functional components (which together thus replaced some of the wheat). All breads were baked twice per week in a local bakery and delivered immediately to the study participants. The weight of each bread was recorded before delivery. In order to determine the amount of bread actually consumed, the subjects were asked to hand in or to document the weight of leftover bread. A sensory panel assessed the test breads for taste, consistence and shelf life.

The standardised diets were provided for $7 \mathrm{~d}$ during the control and intervention phases in the last week of each period. Meals consisting of $1 \mathrm{~d}$ menus were weighed, documented and packed twice per week for all volunteers. The portions included all the food for the duration of the standardised diet $(7 \mathrm{~d})$, mineral water and herbal tea bags. The subjects were instructed to collect and return the leftover food to the supervisor. Volunteers were asked to refrain from eating any fermented or prebiotic and probiotic dairy products, any

Table 1. Characteristics, dietary intake (7d dietary record) and lipid status of all volunteers and the subgroups (non-smokers and smokers) at the start of the study

(Mean values and standard deviations)

\begin{tabular}{|c|c|c|c|c|}
\hline \multirow[b]{2}{*}{ Parameter } & \multicolumn{2}{|c|}{ All volunteers ( $n$ 38) } & \multirow{2}{*}{$\begin{array}{c}\text { Non-smokers }(n 18) \\
\text { Mean }\end{array}$} & \multirow{2}{*}{$\begin{array}{c}\text { Smokers }(n 20) \\
\text { Mean }\end{array}$} \\
\hline & Mean & SD & & \\
\hline Age (years) & $27 \cdot 4$ & 7.5 & $26 \cdot 3$ & 28.4 \\
\hline Height $(m)$ & 1.80 & 0.06 & $1 \cdot 80$ & $1 \cdot 80$ \\
\hline Body mass (kg) & $75 \cdot 0$ & 8.5 & 72.9 & $77 \cdot 0$ \\
\hline $\operatorname{BMI}\left(\mathrm{kg} / \mathrm{m}^{2}\right)$ & $23 \cdot 2$ & $2 \cdot 8$ & $22 \cdot 7$ & 23.7 \\
\hline Energy intake (MJ) & $10 \cdot 0$ & $2 \cdot 6$ & $10 \cdot 1$ & $10 \cdot 0$ \\
\hline Carbohydrate intake (\% El) & $48 \cdot 1$ & $7 \cdot 1$ & $47 \cdot 8$ & 48.4 \\
\hline Fat intake (\% EI) & 34.9 & $6 \cdot 2$ & 35.4 & 34.5 \\
\hline Protein intake (\% El) & $15 \cdot 0$ & $2 \cdot 6$ & 14.5 & $15 \cdot 4$ \\
\hline Dietary fibre $(\mathrm{g} / \mathrm{d})$ & $22 \cdot 2$ & $7 \cdot 7$ & $23 \cdot 2$ & $21 \cdot 3$ \\
\hline Total cholesterol $(\mathrm{mmol} / \mathrm{l})$ & 3.52 & $1 \cdot 14$ & 3.36 & 3.67 \\
\hline LDL-cholesterol (mmol/l) & $2 \cdot 19$ & 0.94 & $2 \cdot 10$ & $2 \cdot 26$ \\
\hline HDL-cholesterol (mmol/l) & 1.00 & 0.30 & 1.02 & 0.98 \\
\hline LDL:HDL ratio & $2 \cdot 24$ & 0.85 & 2.09 & $2 \cdot 38$ \\
\hline TAG $(\mathrm{mmol} / \mathrm{l})$ & 0.81 & 0.52 & 0.65 & 0.95 \\
\hline
\end{tabular}


Table 2. Composition and characteristics of the control bread, prebiotic bread and the prebiotic antioxidant bread (pre-aox-bread) during the intervention study

\begin{tabular}{lccc}
\hline Parameter & Control bread & Prebiotic bread & Pre-aox-bread \\
\hline Total dietary fibre $(\mathrm{g} / 100 \mathrm{~g})$ & 7.78 & 11.3 & 9.03 \\
Inulin $(\mathrm{g} / 100 \mathrm{~g})$ & - & 4.00 & 4.00 \\
Soya fibre $(\mathrm{g} / 100 \mathrm{~g})$ & - & 6.00 & 6.00 \\
Linseed $(\mathrm{g} / 100 \mathrm{~g})$ & - & 4.00 & 4.00 \\
Tomato puree $(\mathrm{g} / 100 \mathrm{~g})$ & - & - & 0.50 \\
Green tea powder $(\mathrm{g} / 100 \mathrm{~g})$ & - & - & 0.75 \\
Oregano $(\mathrm{g} / 100 \mathrm{~g})$ & 0.18 & 0.48 & 0.75 \\
$\alpha$-Tocopherol $(\mathrm{mg} / 100 \mathrm{~g})$ & $<34$ & $<34$ & 4.38 \\
Total lycopene $(\mu \mathrm{g} / 100 \mathrm{~g})$ & $<34$ & $<34$ & 358 \\
$(E)$-Lycopene $(\mu \mathrm{g} / 100 \mathrm{~g})$ & $<41$ & $<41$ & 208 \\
$(E)-\beta$-Carotene $(\mu \mathrm{g} / 100 \mathrm{~g})$ & $<19$ & $<19$ & 67 \\
$(9 Z)-\beta$-Carotene $(\mu \mathrm{g} / 100 \mathrm{~g})$ & $<27$ & $<27$ & 56 \\
$(15 Z)-\beta$-Carotene $(\mu \mathrm{g} / 100 \mathrm{~g})$ & $<32$ & $<32$ & 28 \\
$(E)$-Lutein $(\mu \mathrm{g} / 100 \mathrm{~g})$ & 0.44 & 0.76 & 1.27 \\
TEAC (hydrophilic) $(\mathrm{mmol} / 100 \mathrm{~g})$ & 0.04 & 0.07 & 2.18 \\
TEAC (lipophilic) $(\mathrm{mmol} / 100 \mathrm{~g})$ & & & \\
\hline
\end{tabular}

TEAC, trolox equivalent antioxidant capacity.

other bread, soya products, tomato products, green tea or supplements of vitamins and minerals.

\section{Analytical methods}

Blood samples were centrifuged for $20 \mathrm{~min}$ at $1600 \mathrm{~g}$ and the serum was frozen immediately at $-80^{\circ} \mathrm{C}$. $\alpha$-Tocopherol in serum was measured according to Rettenmaier \& Schüep (1992) using HPLC (HPLC-LC 10, Shimadzu, Tokyo, Japan; fluorescence detector RF 10AXL, Shimadzu; column, nucleosil $100 \mathrm{NH}_{2}$; flow rate, $0.8 \mathrm{ml} / \mathrm{min}$; eluent, $96 \%$ n-hexan, $4 \%$ 2-propanol; $292 \mathrm{~nm} / 330 \mathrm{~nm}$; injection volume, $20 \mu \mathrm{l}$ ). Uric acid was determined photometrically via a test kit on a Synchron LX ${ }^{\circledR}$ (Beckman Coulter, Inc., Fullerton, CA, USA).

Blood for immunological assays was collected in EDTAcoated tubes and immediately analysed. The phagocytic activity was measured with the test kit Phagotest ${ }^{\circledR}$ (Orpegen, Heidelberg, Germany) that analyses the percentage of granulocytes which phagocytise fluoresceinisothiocyanat-marked Escherichia coli. The determination was carried out using fluorescence microscopy. The 'oxidative burst' (intracellular destruction of oxygen-dependent mechanisms) was measured by flow cytometry using the testkit Phagoburst ${ }^{\circledR}$ (Orpegen). To analyse surface-marked lymphocytes, $100 \mu l$ heparinised blood were incubated with $20 \mu \mathrm{l}$ fluoresceinisothiocyanatmarked antibodies. Lysis of erythrocytes occurred after adding $2 \mathrm{ml}$ fluorescence-activated cell sorter solution (Becton Dickinson, Franklin Lakes, NJ, USA). Cells were then measured by flow cytometer. Two thousand cells per field of lymphocytes were detected and the percentage of the surface-marked lymphocytes was determined.

Samples were immediately placed in dark containers to avoid any unnecessary exposure to light, and antioxidant parameters were measured in plasma and in urine with the ferric reducing ability of plasma (FRAP) assay (Benzie \& Strain, 1996). To measure the antioxidant activity of the test breads, the trolox equivalent antioxidant capacity assay for hydrophilic antioxidants (Miller et al. 1993) and the trolox equivalent antioxidant capacity assay for lipophilic antioxidants (Boehm et al. 2002) were performed. Total phenols in urine were photometrically detected using the Folin-Ciocalteau method (Singleton \& Rossi, 1965). Results are given as total polyphenol excretion per $24 \mathrm{~h}$ in gallic acid equivalents (GAE). The same method was used to analyse GAE in plasma after incubation with $\mathrm{HCl}, \mathrm{NaOH}$ and meta-phosphoric acid. After adding an acetone-water mixture the resulting residue was used for performing the determinations. Total $\beta$-carotene, isomer $(E)$ - $\beta$-carotene, total lycopene and isomer $(E)$-lycopene in plasma were analysed by HPLC (column C30 Vertex YMC carotenoid S-5 $\mu \mathrm{m}$; YMC, Schermbeck, Germany) and diode array detector (L4500; Merck, Darmstadt, Germany) using the method of Boehm (2001). The total radical-trapping antioxidant parameter (TRAP) was measured with a fluorimeter according to the procedure described by Ghiselli et al. (1995). The photosensitive chemoluminescence (PCL) method, using trolox as standard, was performed according to the method of Popov \& Lewin (1999) using the Photochem $^{\circledR}$ (Analytik Jena AG, Jena, Germany).

\section{Statistics}

The data were tested for significant differences between periods with no adjustment for general linear model-repeated measurements. To compare differences between the two types of bread as well as between the smokers and non-smokers, the Mann-Whitney $U$ test was used as a non-parametric test for two independent values. For each comparison, a value of $P<0.05$ was considered to be statistically significant. All statistical calculations were performed with the Statistical Package for the Social Sciences (SPSS/PC + , version 11.5; SPSS Inc., Chicago, IL, USA).

\section{Results}

\section{Analysis of the breads}

The content of total dietary fibre was highest in the prebiotic bread, followed by the pre-aox-bread (Table 2). The trolox equivalent antioxidant capacity value (hydrophilic version of the assay) of the pre-aox-bread was approximately twice as high as that of the prebiotic bread and the trolox equivalent 
antioxidant capacity value (lipophilic version of the assay) of the pre-aox-bread was approximately thirty times higher than that of the prebiotic bread. The content of $\alpha$-tocopherol in the pre-aox-bread was about ten times that of the prebiotic bread. The carotenoids (total lycopene, $(E)$-lycopene, $(E)$ - $\beta$-carotene, (9Z)- $\beta$-carotene, (15Z)- $\beta$-carotene and (E)-lutein), detected in the pre-aox-bread, were not present either in the control bread or in the prebiotic bread.

\section{Intake}

The average intake of all breads during the control period was 202 (SD 57) g/d, which was significantly higher than before the start of the study (166 (SD 61) g). In the intervention period the bread intake was 229 (SD 64) g for prebiotic bread and 189 (SD 70) g for pre-aox-bread. None of the volunteers complained of any difficulties while consuming the test breads. In fact, the subjects graded the taste, the consistence and the shelf life of all three breads as 'good' (scale of rating given was 1 for 'excellent'; 2 for 'good' and 3 for 'sufficient'). The placebo bread was graded to be better in taste and shelf life than the two intervention breads. Similar grading results were obtained by a professional sensory panel.

\section{Body composition of the subjects and diets}

BMI, body lean mass and body fat mass remained stable during the control and intervention periods (Table 3). Also the average daily intake of energy, fat, protein and carbohydrates revealed no changes during the control and intervention periods. But a significant increase of the average daily intake was observed for total dietary fibre and $\alpha$-tocopherol. Compared with the start, BMI significantly decreased after the intervention (23.2 to $23.0 \mathrm{~kg} / \mathrm{m}^{2}$ ), whereas the energy intake remained stable.

\section{Contents of antioxidants and antioxidant capacity}

There was a significant increase $(P=0.018)$ of the FRAP of participants consuming the pre-aox-bread, but no increase when consuming the prebiotic bread (Table 4). This increase in FRAP value was significant for the non-smokers who

Table 3. Parameters of the body composition and dietary intake of the subjects during the study

(Mean values and standard deviations for thirty-eight male subjects)

\begin{tabular}{|c|c|c|c|c|}
\hline \multirow[b]{2}{*}{ Parameters } & \multicolumn{2}{|c|}{ Control } & \multicolumn{2}{|c|}{ Intervention } \\
\hline & Mean & SD & Mean & SD \\
\hline $\mathrm{BMI}\left(\mathrm{kg} / \mathrm{m}^{2}\right)$ & $23 \cdot 2$ & 2.9 & $23 \cdot 0$ & 3.0 \\
\hline Body lean mass (kg) & $62 \cdot 8$ & $5 \cdot 8$ & $62 \cdot 2$ & $6 \cdot 0$ \\
\hline Body fat mass $(\mathrm{kg})$ & $12 \cdot 1$ & 4.6 & $12 \cdot 2$ & 4.9 \\
\hline $\mathrm{El}(\mathrm{MJ} / \mathrm{d}) \dagger$ & $10 \cdot 7$ & $1 \cdot 2$ & $10 \cdot 6$ & $1 \cdot 2$ \\
\hline Carbohydrate intake (\%EI)† & $47 \cdot 8$ & 3.5 & $47 \cdot 1$ & 3.8 \\
\hline Protein intake $(\% \mathrm{El}) \ddagger$ & $14 \cdot 7$ & $1 \cdot 1$ & 14.9 & $1 \cdot 1$ \\
\hline Fat intake $(\% \mathrm{El}) \ddagger$ & $37 \cdot 3$ & $3 \cdot 7$ & $37 \cdot 8$ & $4 \cdot 0$ \\
\hline Dietary fibre $(\mathrm{g} / \mathrm{d}) \ddagger$ & $34 \cdot 2$ & $5 \cdot 0$ & $39 \cdot 7^{\star}$ & 8.6 \\
\hline$\alpha$-Tocopherol $(\mathrm{mg} / \mathrm{d}) \ddagger$ & $6 \cdot 89$ & 0.67 & $11 \cdot 3^{*}$ & $4 \cdot 4$ \\
\hline
\end{tabular}

El, energy intake.

${ }^{*}$ Mean value was significantly different from that for the control period $(P=0.000)$.

†Data calculated using PRODI 4.4 software (Nutri-Science GmbH, Freiburg, Germany).

‡Data from analysed food of the standardised diet (see p. 350). consumed the pre-aox-bread, whereas there were no changes in FRAP value for the smokers who ate the pre-aox-bread.

The concentrations of total phenols (measured in GAE) remained stable (792 to $797 \mathrm{mg} / \mathrm{l}$ after consuming the prebiotic bread and 813 to $806 \mathrm{mg} / \mathrm{l}$ after intervention with the pre-aox-bread).

Total $\beta$-carotene, $(E)$ - $\beta$-carotene, total lycopene and $(E)$-lycopene significantly increased in the pre-aox group during intervention (Table 4), whereas no effects were seen in the subjects who consumed prebiotic bread. The analysed carotenoids increased for smokers and non-smokers after consumption of the pre-aox-bread, but showed a higher statistical significance in the non-smoking group. The increase of the $(E)$-lycopene in the plasma of non-smokers was significantly higher $(P=0.045)$ compared with the group of smokers who ate the pre-aox-bread. The concentrations of $\alpha$-tocopherol and uric acid significantly rose after consumption of both types of bread. This increase of $\alpha$-tocopherol and uric acid was more significant for the pre-aox-bread group $(P=0.000$ and $P=0.001$, respectively) than for the prebiotic bread group $(P=0.027$ and $P=0 \cdot 006$, respectively; Table 4).

\section{Total phenols and antioxidant capacity in urine}

TRAP and PCL increased significantly after consumption of the pre-aox-bread $(10.6$ to $14.9 \mathrm{mmol} / \mathrm{d}, P=0.010$; and 2.5 to $3.1 \mathrm{mmol} / \mathrm{d}, P=0 \cdot 043$, respectively) as well as after consuming the prebiotic bread $(13.2$ to $19.1 \mathrm{mmol} / \mathrm{d}, P=0.007$; and 3.2 to $3.9 \mathrm{mmol} / \mathrm{d}$. $P=0.019$, respectively). No significant effects on the mean values of FRAP and GAE in urine were seen after intervention. When comparing both types of breads, and the response parameters of smokers $v$. non-smokers, there were no significant differences for GAE, FRAP, TRAP and PCL.

\section{Immunological parameters}

The numbers of leucocytes $(n / \mu l)$ in the blood did not change after the intervention period compared with the control period. However, the numbers of lymphocytes and granulocytes significantly increased from the start to the intervention period (data not shown). The relative distribution of the leucocytes (lymphocytes, monocytes and granulocytes) was 37.4 (SD 6.7), 7.69 (SD 1.9) and 55.1 (SD 6.5) \%, respectively, at the start and remained stable during the trial. The fraction of CD19 in the lymphocytes increased significantly after intervention for smokers and those on prebiotic bread (Table 5). There was a similar significant increase after intervention in smokers irregardless of the type of bread consumed ( $n$ 20; data not shown). Intercellular adhesion molecule-1 (ICAM-1) and CD3 + NK + decreased significantly after intervention. This decrease of ICAM- 1 was also found in the subjects testing the prebiotic bread as well as in the non-smokers consuming both breads ( $n$ 18). The decrease of ICAM-1, however, was significant only in the group of non-smokers who consumed the pre-aox-bread ( $n$ 8). No differences were found for ICAM-1 and CD19 after intervention when comparing the test breads $(19: 19)$ and when comparing all smokers to non-smokers (20:18). The decrease of CD3 $+\mathrm{NK}+$ was observed in all tested groups (smokers, non-smokers, consumers of the prebiotic bread and the pre-aox-bread). CD3 + HLA-DR + (activated T-cells) increased after consuming the prebiotic bread.

Phagotest ${ }^{\circledR}$ and Phagoburst ${ }^{\circledR}$ values did not change after the intervention. Phagoburst ${ }^{\circledR}$ decreased after the control period 
Table 4. Plasma concentrations of $\beta$-carotene, lycopene, $\alpha$-tocopherol, uric acid and ferric-reducing ability of plasma (FRAP) values* (Mean values and standard deviations)

\begin{tabular}{|c|c|c|c|c|c|c|c|}
\hline \multirow{3}{*}{$\begin{array}{l}\text { Parameter } \\
\text { Total } \beta \text {-Carotene }(\mu \mathrm{mol} / \mathrm{l})\end{array}$} & \multirow{2}{*}{\multicolumn{2}{|c|}{ Intervention bread and smoking status }} & \multicolumn{2}{|c|}{ Control } & \multicolumn{2}{|c|}{ Intervention } & \multirow[b]{2}{*}{$P$} \\
\hline & & & \multirow{2}{*}{$\frac{\text { Mean }}{1.46}$} & \multirow{2}{*}{$\frac{S D}{1.09}$} & \multirow{2}{*}{$\frac{\text { Mean }}{1.35}$} & \multirow{2}{*}{$\begin{array}{l}\text { SD } \\
0.79\end{array}$} & \\
\hline & Bread & Prebiotic (n 19) & & & & & NS \\
\hline & & Pre-aox-bread ( $n$ 19) & $1 \cdot 15$ & 0.64 & 1.41 & 0.69 & 0.001 \\
\hline & Pre-aox-bread & Non-smokers ( $n$ 8) & 1.36 & 0.73 & 1.63 & 0.87 & 0.017 \\
\hline & & Smokers $(n 11)$ & 1.00 & 0.54 & 1.25 & 0.51 & 0.026 \\
\hline \multirow[t]{4}{*}{$(E)-\beta$-Carotene $(\mu \mathrm{mol} / \mathrm{l})$} & Bread & Prebiotic $(n 19)$ & 1.41 & 1.00 & $1 \cdot 27$ & 0.72 & NS \\
\hline & & Pre-aox-bread (n 19) & 1.03 & 0.55 & $1 \cdot 24$ & 0.62 & 0.000 \\
\hline & Pre-aox-bread & Non-smokers $(n 8)$ & $1 \cdot 22$ & 0.63 & 1.49 & 0.76 & 0.010 \\
\hline & & Smokers $(n 11)$ & 0.89 & 0.46 & 1.05 & 0.45 & 0.023 \\
\hline \multirow[t]{4}{*}{ Total lycopene $(\mu \mathrm{mol} / \mathrm{l})$} & Bread & Prebiotic $(n 19)$ & 1.39 & 0.52 & 1.37 & 0.73 & NS \\
\hline & & Pre-aox-bread $(n 19)$ & $1 \cdot 13$ & 0.63 & 1.89 & 0.61 & 0.000 \\
\hline & Pre-aox-bread & Non-smokers $(n 8)$ & $1 \cdot 13$ & 0.65 & 2.04 & 0.44 & 0.002 \\
\hline & & Smokers $(n 11)$ & $1 \cdot 14$ & 0.64 & 1.79 & 0.71 & 0.012 \\
\hline \multirow[t]{4}{*}{$(E)$-Lycopene $(\mu \mathrm{mol} / \mathrm{l})$} & Bread & Prebiotic $(n 19)$ & 0.53 & $0 \cdot 17$ & 0.50 & 0.22 & NS \\
\hline & & Pre-aox-bread ( $n$ 19) & 0.46 & 0.26 & 0.73 & 0.24 & 0.000 \\
\hline & Pre-aox-bread & Non-smokers ( $n$ 8) & 0.44 & 0.21 & 0.81 & 0.20 & 0.000 \\
\hline & & Smokers $(n 11)$ & 0.47 & 0.29 & 0.68 & 0.27 & 0.050 \\
\hline \multirow[t]{4}{*}{$\alpha$-Tocopherol $(\mu \mathrm{mol} / \mathrm{l})$} & Bread & Prebiotic (n 19) & $18 \cdot 4$ & $5 \cdot 1$ & $20 \cdot 1$ & 4.9 & 0.027 \\
\hline & & Pre-aox-bread $(n 19)$ & $19 \cdot 2$ & $5 \cdot 0$ & $22 \cdot 7$ & $6 \cdot 1$ & 0.000 \\
\hline & Pre-aox-bread & Non-smokers ( $n$ 8) & $19 \cdot 9$ & $4 \cdot 8$ & $22 \cdot 3$ & $5 \cdot 1$ & NS \\
\hline & & Smokers $(n 11)$ & $18 \cdot 8$ & 5.4 & $23 \cdot 1$ & $6 \cdot 9$ & 0.003 \\
\hline \multirow[t]{4}{*}{ Uric acid $(\mu \mathrm{mol} / \mathrm{l})$} & Bread & Prebiotic $(n 19)$ & 310 & 59 & 339 & 47 & 0.006 \\
\hline & & Pre-aox-bread $(n 19)$ & 313 & 67 & 354 & 62 & 0.001 \\
\hline & Pre-aox-bread & Non-smokers $(n 8)$ & 307 & 81 & 348 & 80 & 0.045 \\
\hline & & Smokers ( $n$ 11) & 317 & 56 & 357 & 49 & 0.018 \\
\hline \multirow[t]{4}{*}{ FRAP $(\mu \mathrm{mol} / \mathrm{l})$} & Bread & Prebiotic $(n 19)$ & 1216 & 310 & 1191 & 251 & NS \\
\hline & & Pre-aox-bread (n 19) & 1210 & 168 & 1280 & 149 & 0.018 \\
\hline & Pre-aox-bread & Non-smokers $(n 8)$ & 1147 & 131 & 1256 & 175 & 0.019 \\
\hline & & Smokers $(n 11)$ & 1256 & 182 & 1298 & 134 & NS \\
\hline
\end{tabular}

Pre-aox-bread, prebiotic antioxidant bread.

* Subjects were divided into groups consuming the prebiotic bread or pre-aox-bread during the intervention and in non-smokers and smokers consuming the pre-aox-bread.

and remained at the lower level until the end of the study. There was a tendency of increased values of the Phagotest ${ }^{\circledR}(P=0 \cdot 076)$ from the start to the intervention. Other immunological parameters analysed (CD3, CD4, CD8, CD4:CD8, NK, CD57, $\mathrm{CD} 8+\mathrm{CD} 57+, \quad \mathrm{CD} 25, \quad \mathrm{CD} 4+\mathrm{CD} 25+, \quad \mathrm{CD} 122$ and $\mathrm{CD} 4+\mathrm{CD} 54+$ ) did not change after the intervention period.

\section{Discussion}

\section{Antioxidant capacity}

The FRAP value increased in the plasma of subjects testing the pre-aox-bread, particularly in the group of non-smokers ( $n$ 8). In contrast, the concentrations of GAE in plasma remained unchanged after consumption of both pre-aox-bread and prebiotic bread. In general, the antioxidant capacity (in this case the FRAP assay) has been shown to correlate with the concentrations of total phenols (Serafini et al. 1998). Thus, an increase of antioxidant activity in plasma without a change in GAE could be due to a modification of the phenolic pattern. Moreover, it has been shown that polyphenols may be capable of modifying the antioxidant capacity (Pedersen et al. 2000). It has previously been shown that after intervention with a beverage rich in antioxidants GAE did not result in a change of total phenolics in plasma and in serum whereas the antioxidant capacity increased significantly (Boehm et al. 2004). Most of the studies on the potential antioxidative effects of tea in human subjects have reported an increase of the antioxidant capacity in plasma. Benzie et al. (1999) observed a rise of the

Table 5. Selected immunological parameters of blood dependent on the type of bread (\% of lymphocytes) (Mean values and pooled standard deviations for nineteen male subjects)

\begin{tabular}{|c|c|c|c|c|c|c|c|}
\hline & \multicolumn{3}{|c|}{ Pre-aox-bread ( $n$ 19) } & \multicolumn{3}{|c|}{ Prebiotic bread $(n 19)$} & \multirow[b]{2}{*}{ Pooled SD (n 38) } \\
\hline & C & 1 & $P^{\star}$ & C & I & $P^{\star}$ & \\
\hline CD19 & 10.5 & $10 \cdot 8$ & NS & 10.5 & $11 \cdot 8$ & 0.023 & 3.35 \\
\hline ICAM-1 & $56 \cdot 2$ & $54 \cdot 0$ & NS & $57 \cdot 0$ & $53 \cdot 8$ & 0.014 & 9.08 \\
\hline $\mathrm{CD} 3+\mathrm{NK}+$ & $2 \cdot 37$ & 1.74 & 0.002 & $3 \cdot 21$ & 2.42 & 0.005 & $2 \cdot 35$ \\
\hline CD3 + HLA-DR + & $5 \cdot 16$ & 4.58 & NS & 5.53 & $6 \cdot 63$ & 0.017 & $3 \cdot 12$ \\
\hline
\end{tabular}

Pre-aox-bread; prebiotic antioxidant bread; C, control period; I, intervention period; CD, cluster of differentiation; ICAM-1, intercellular adhesion molecule-1; NK, natural killer; HLA, human leucocyte antigen; DR, related to HLA-D locus.

* Statistical significance of difference. 
FRAP activity in plasma 20-40 min after ingestion of green tea. Similar increases of the FRAP activity have also been reported for green and black tea (Leenen et al. 2000; Langley-Evans, 2000). In a study investigating sixty patients with coronary artery disease, however, there was no significant increase of FRAP subsequent to black tea consumption (Duffy et al. 2001).

Unexpectedly, the correlations between uric acid and FRAP were not significant $(r 0.29$ after consumption of the prebiotic bread and $r 0.44$ after consuming the pre-aox-bread). Nevertheless, uric acid seems to be a strong contributor to the FRAP value. Fernandez-Pachon et al. (2005) also found a correlation between uric acid and the antioxidant capacity determined with FRAP.

The carotenoids in plasma were also significantly increased after the consumption of the pre-aox-bread, whereas no changes were observed in the prebiotic bread group. The most obvious effect was seen in the group of non-smokers who consumed the pre-aox-bread. Levels of all four carotenoids investigated rose significantly.

Three parameters (total lycopene, total $\beta$-carotene and $(E)$ $\beta$-carotene) were significantly enhanced and $(E)$-lycopene increased $(P=0.05)$ in the group of smokers who consumed the pre-aox-bread ( $n$ 11). In addition, the levels of significance for increased carotenoid concentrations were higher for nonsmokers than for smokers. The difference of the $(E)$-lycopene content in plasma between smokers and non-smokers after intervention with pre-aox-bread was statistically significant. It may be assumed that the differences between smokers and non-smokers for total lycopene, total $\beta$-carotene, $(E)-\beta$-carotene, and FRAP might have been significant with more participants. The low increase of antioxidants in plasma of smokers is supported by the findings of Handelman et al. (1996), who observed a destruction of carotenoids and tocopherols in human plasma by cigarette smoke.

There was a more pronounced increase of $\alpha$-tocopherol in plasma after pre-aox-bread $(P=0 \cdot 000)$ than after the prebiotic bread. This was reflected by higher concentrations of $\alpha$-tocopherol in this bread in comparison with the control period and the prebiotic bread. A high intake of $\alpha$-tocopherol (more than $40 \mathrm{mg} / \mathrm{d}$ ) was associated with a lower risk of CHD in both men (Rimm et al. 1993) and women (Stampfer et al. 1993).

TRAP and PCL measured in urine increased significantly after consumption of both intervention breads. However, FRAP and GAE in urine remained unchanged. As with the effects observed in plasma, this might indicate a rise of the antioxidant capacity in urine whereas the total amount of phenolic components remained stable. In a previous study, an increase of FRAP in urine was found 60 to 90 min after consumption of green tea (Benzie et al. 1999), which was a time frame considerably below the one we used for our analyses (weeks). Thus, these differences at which the measurements were performed may also explain the different effects observed. Similarly, the differences in the antioxidative activity may also depend on the assay used (Day et al. 1997; Serafini et al. 1998; Prior \& Cao, 1999).

These findings demonstrate an immediate effect of a food, enriched in antioxidants, in human subjects. The notable effect of antioxidants might be explained by the results of a study in which natural antioxidants had an up to sixteen times higher antioxidant potential than synthetic ones (Kranl et al. 2005).

\section{Immunological parameters}

The majority of the immunological parameters from peripheral blood showed no fluctuation, whereas four markers changed after consuming the prebiotic bread. ICAM-1 is responsible for co-operation between cells and is, for instance, up regulated in response to virus infection and cellular stress (Roebuck \& Finnegan, 1999). It has been shown that patients with ischaemic stroke also had elevated concentrations of ICAM-1 compared with the control group (Sanchez-Moreno et al. 2004). In the smokers and the non-smokers who ate the pre-aox-bread, ICAM-1 decreased after the intervention period. ICAM-1 also decreased in a human study after consumption of a symbiotic yoghurt (Lactobacillus acidophilus and Bifidobacterium sp. and the oligofructose Fibrilose ${ }^{\circledR}$ F90; Klein et al. 2003). The concentration of ICAM-1 furthermore changed after the intake of Lactobacillus paracasei incorporated into sausages (Jahreis et al. 2002). These observations indicate that ICAM-1 is influenced by the intestinal microflora. CD19, which increased for smokers and after the consumption of the prebiotic bread, was also enhanced in participants in a study subjected to stress for $5 \mathrm{~d}$ (sleep deprivation, energy restriction and psychological stress) during military training (Gomez-Merino et al. 2005). A decline of CD19 cells was observed in a survey of 100 healthy volunteers only in participants aged $>50$ years (Jentsch-Ullrich et al. 2005). CD3 + NK + was the only immunological parameter which changed after intake of the pre-aox-bread. This is probably due to functional effects.

In vitro studies showed a decrease of oxidative burst activity after incubating macrophages (isolated from fish) with high concentrations of $\beta$-glucans (Robertson et al. 1994; Schmitz, 2004). This could explain the decrease of Phagoburst ${ }^{\circledR}$ from the beginning to the control period. In fact, it looks as if the modulation was more due to consuming higher quantities of bread (during periods of control and intervention) than to consuming the prebiotic or pre-aox-bread. Kelly-Quagliana et al. (2003) found a higher phagocytic activity of peritoneal macrophages and a greater activity of natural killer cells of splenocytes after feeding mice with inulin. The immune functions were primarily affected via gut-associated lymphoid tissues in a study using rats fed a prebiotic supplement (inulin enriched with oligofructose) for 4 weeks (Roller et al. 2004). This can explain the minor effects of prebiotic bread in the present trial on the immunological parameters of peripheral blood as opposed to parameters of the gut-associated lymphoid tissues.

In conclusion, moderate amounts of prebiotics and natural antioxidants incorporated into a main food had an influence on several parameters of the immune system. The added antioxidants enhanced the levels of carotenoids and antioxidative capacity in the plasma (measured as FRAP). There were also changes more related to consuming higher quantities of bread than due to the functional ingredients. These include an effect on the oxidative burst of granulocytes. The antioxidants and the antioxidant capacity, in particular, responded to the functional components. There seem to be indications for differences on the antioxidant status between smokers and non-smokers, but there were marked differences related to the pharmacology (absorption, bioavailability, excretion) of antioxidants. We assume that consuming antioxidative components incorporated into basic food, as opposed to taking supplements, lowers the 
risk of antioxidants over consumption and its unpredictable consequences (as observed in the CARET and ATBC study and its follow-ups: Rapola et al. 1997; Virtamo et al. 1998; Markareetta et al. 2004) might be minimised. Long-term research in the field of moderately enriched food with antioxidants and its risks for CHD is necessary, especially with regard to the smoking status of the participants.

\section{Acknowledgements}

We thank the volunteers of the study as well as Ute Helms, Peter Moeckel and Irmtraut Schmuck for their excellent technical assistance. We are also indebted to Rainer Schubert, $\mathrm{PhD}$, for his help with the statistical analysis and finally we extend our appreciation to the employees at the local Feid bakery for their outstanding co-operation.

\section{References}

Alles MS, Hautvast JGAL, Nagengast FM, Harteming R, Van Laere KM \& Jansen JBMJ (1996) Fate of fructooligosaccharides in the human intestine. Br J Nutr 76, 211-221.

Anderson JW \& Hanna TJ (1999) Impact of nondigestible carbohydrates on serum lipoproteins and risk for cardiovascular disease. J Nutr 129, 1457-1466.

Arai S (1996) Studies on functional foods in Japan - state of the art. Biosci Biotechnol Biochem 60, 9-15.

Benzie IFF \& Strain JJ (1996) The ferric reducing ability of plasma (FRAP) as a measure of "antioxidant power": the FRAP assay. Anal Biochem 239, 70-76.

Benzie IFF, Szeto YT, Strain JJ \& Tomlinson B (1999) Consumption of green tea causes rapid increase in plasma antioxidant power in humans. Nutr Cancer 34, 83-87.

Boehm V (2001) Use of column temperature to optimize carotenoid isomer separation by $\mathrm{C} 30$ high performance liquid chromatography. J Sep Sci 24, 955-959.

Boehm V, Netzel M, Kler A, Marx S, Weiss M \& Geiss K-R (2004) Antioxidant capacity of human plasma and serum as affected by a single dose of a beverage rich in antioxidants - use of three different assay systems. J Food Agric Environm 2, 74-78.

Boehm V, Puspitasari-Nienaber NL, Ferruzzi MG \& Schwartz SJ (2002) Trolox equivalent antioxidant capacity of different geometrical isomers of $\alpha$-carotene, $\beta$-carotene, lycopene, and zeaxanthin. J Agric Food Chem 50, 221-226.

Brighenti F, Casiraghi MC, Canzi E \& Ferrari A (1999) Effects of consumption of a ready-to-eat-breakfast cereal containing inulin on the intestinal milieu and blood lipids in healthy male volunteers. Eur J Clin Nutr 53, 726-733.

Buddington KK, Danahoo JB \& Buddington RK (2002) Dietary oligofructose and inulin protect mice from enteric and systemic pathogens and tumor inducers. J Nutr 132, 472-477.

Causey JL, Feirtag JM, Gallaher DD, Tungland BC \& Slavin JL (2000) Effects of dietary inulin on serum lipids, blood glucose and the gastrointestinal environment in hypercholesterolemic men. Nutr Res 20, 191-201.

Connor SL, Ojeda LS, Sexton G, Weidner G \& Connor WE (2004) Diets lower in folic acid and carotenoids are associated with the coronary disease epidemic in Central and Eastern Europe. $J$ Am Diet Assoc 104, 1793-1799.

Cooper DA, Eldridge AL \& Peters JC (1999) Dietary carotenoids and certain cancers, heart disease, and age-related macular degeneration: a review of recent research. Nutr Rev 57, 201-214.

Coudray C, Bellanger J, Castiglia-Delavaud C, Rémésy C, Vermorel M \& Rayssignuier Y (1997) Effect of soluble or partly soluble dietary fibers supplementation on absorption and balance of calcium, magnesium, iron and zinc in healthy young men. Eur $J$ Clin Nutr 51, 375-380.

Day AP, Kemp HJ, Bolton C, Hartog M \& Stansbie D (1997) Effect of concentrated red grape juice consumption on serum antioxidant capacity and low-density lipoprotein oxidation. Ann Nutr Metab 41, 353-357.

Duffy SJ, Keaney JF Jr, Holbrook M, Gokce N, Swerdloff PL, Frei B \& Vita JA (2001) Short- and long-term black tea consumption reverses endothelial dysfunction in patients with coronary artery disease. Circulation 104, 151-156.

Fernandez-Pachon MS, Villano D, Troncoso AM \& Garcia-Parrilla MC (2005) Antioxidant capacity of plasma after red wine intake in human volunteers. J Agric Food Chem 53, 5024-5029.

Ghiselli A, Serafini M, Maiani G, Azzini E \& Ferro-Luzzi A (1995) A fluorescence-based method for measuring total plasma antioxidant capability. Free Rad Biol Med 18, 29-36.

Gibson GR, Rastall RA \& Roberfroid MB (1999) Prebiotics. In Colonic Microbiota, Nutrition and Health, pp. 101-124 [GR Gibson and MB Roberfroid, editors]. Kluwer: Dordrecht, The Netherlands.

Glei M, Habermann N, Osswald K, Seidel C, Persin C, Jahreis G \& Pool-Zobel BL (2005) Assessment of DNA damage and its modulation by dietary and genetic factors in smokers using the comet assay: a biomarker model. Biomarkers 10, 203-217.

Gomez-Merino D, Drogou C, Chennaoui M, Tiollier E, Mathieu J \& Guezennec CY (2005) Effects of combined stress during intense training on cellular immunity, hormones and respiratory infections. Neuroimmunomodulation 12, 164-172.

Griffin IJ, Davilla PM \& Abrams SA (2002) Non-digestible oligosaccharides and calcium absorption in girls with adequate calcium intakes. Br J Nutr 87, S187-S191.

Handelman GJ, Packer L \& Cross CE (1996) Destruction of tocopherols, carotenoids, and retinol in human plasma by cigarette smoke. Am J Clin Nutr 63, 559-565.

Hertog MGL, Feskens EJM, Hollman PCH, Katan MB \& Kromhout D (1993) Dietary antioxidant flavonoids and risk of coronary heart disease: the Zutphen Elderly Study. Lancet 342, 1007-1011.

Jahreis G, Vogelsang H, Kiessling G, Schubert R, Bunte C \& Hammes WP (2002) Influence of probiotic sausage (Lactobacillus paracasei) on blood lipids and immunological parameters of healthy volunteers. Food Res Int 35, 133-138.

Jentsch-Ullrich K, Koenigsmann M, Mohren M \& Franke A (2005) Lymphocyte subsets' reference ranges in an age- and genderbalanced population of 100 healthy adults - a monocentric German study. Clin Immunol 116, 192-197.

Jian L, Du CJ, Lee AH \& Binns CW (2005) Do dietary lycopene and other carotenoids protect against prostate cancer? Int J Cancer 113, 1010-1014.

Kelly-Quagliana KA, Nelson PD \& Buddington RK (2003) Dietary oligofructose and inulin modulate immune functions in mice. Nutr Res 23, 257-267.

Klein A, Vogelsang H, Kuhnt K \& Jahreis G (2003) Probiotika und deren Wirkung auf das Immunsystem (Probiotics and their effect on the immune system). Proc German Nutr Soc 70, 5.

Kranl K, Schlesier K, Bitsch R, Hermann H, Rohe M \& Boehm V (2005) Comparing antioxidative additives and secondary plant products - use of different assays. Food Chem 93, 171-175.

Langley-Evans SC (2000) Consumption of black tea elicits an increase in plasma antioxidant potential in humans. Int J Food Sci Nutr 5, 309-315.

Lee KW, Lee HJ \& Lee CY (2004) Vitamins, phytochemicals, diets, and their implementation in cancer chemoprevention. Crit Rev Food Sci Nutr 44, 437-452.

Leenen R, Roodenburg AJ, Tijburg LB \& Wiseman SA (2000) A single dose of tea with or without milk increases plasma antioxidant activity in humans. Eur J Clin Nutr 54, 87-92. 
Letexier D, Diraison F \& Beylot M (2003) Addition of inulin to a moderately high-carbohydrate diet reduces hepatic lipogenesis and plasma triacylglycerol concentrations in humans. Am J Clin Nutr 77, 559-564.

McKay DL \& Blumberg JB (2002) The role of tea in human health: an update. J Am Coll Nutr 21, 1-13.

Markareetta E, Törnwall ME, Virtamo J, Korhonen PA, Virtanen MJ, Taylor PR, Albanes D \& Huttunen JK (2004) Effect of $\alpha$-tocopherol and $\beta$-carotene supplementation on coronary heart disease during the 6-year post-trial follow-up in the ATBC study. Eur Heart J 25, 1171-1178.

Miller NJ, Rice-Evans CA, Davies MJ, Gopinathan V \& Millner A (1993) A novel method for measuring antioxidant capacity and its application to monitoring the antioxidant status in premature neonates. Clin Sci 84, 407-412.

Murr C, Schroecksnadel K, Winkler C, Ledochowski M \& Fuchs D (2005) Antioxidants may increase the probability of developing allergic diseases and asthma. Med Hypoth 64, 973-977.

Nikoleit D (1997) Carotinoide natürlichen Ursprungs - wichtige physiologische Modulatoren, mehr als nur Provitamin A (Naturally occuring carotinoid - important physiological modulators more than only provitamin A). Vitaminspur 12, 5-19.

Nkondjock A, Ghadirian P, Johnson KC \& Krewski D (2005) Dietary intake of lycopene is associated with reduced pancreatic cancer risk. J Nutr 135, 592-597.

Pedersen CB, Kyle J, Jenkinson AM, Gardner PT, McPhail DB \& Duthie GG (2000) Effects of blueberry and cranberry juice consumption on the plasma antioxidant capacity of healthy female volunteers. Eur J Clin Nutr 54, 405-408.

Peters U, Poole C \& Arab L (2001) Does tea affect cardiovascular disease? A meta-analysis. Am J Epidemiol 154, 495-503.

Pool-Zobel BL, Van Loo J \& Roberfroid MB (2002) Experimental evidences on the potential of prebiotic fructans to reduce the risk of colon cancer. Br J Nutr 87, 273-281.

Popov I \& Lewin G (1999) Antioxidative homeostasis: characterization by means of chemiluminescent technique. In Methods in Enzymology, vol. 300, Oxidants and Antioxidants part B [L Packer, editor]. San Diego, New York, Boston, London, Sydney, Tokyo and Toronto: Academic Press.

Prior RL \& Cao GH (1999) In vivo total antioxidant capacity: comparison of different analytical methods. Free Radical Biol Med 27, 1173-1171.

Rajasekhar D, Srinivasa RPV, Latheef SA, Saibaba KS \& Subramanyam G (2004) Association of serum antioxidants and risk of coronary heart disease in South Indian population. Indian J Med Sci 58, 465-471.

Rapola JM, Virtamo J, Ripatti S, Huttunen JK, Albanes D, Taylor PR $\&$ Heinonen OP (1997) Randomised trial of $\alpha$-tocopherol and $\beta$ carotene supplements on incidence of major coronary events in men with previous myocardial infarction. Lancet 349, 1715-1720.

Reddy BS (1999) Possible mechanisms by which pro- and prebiotics influence colon carcinogenesis and tumor growth. J Nutr 129, $1478-1482$.

Rettenmaier R \& Schüep W (1992) Determination of vitamins A and E in liver tissue. Int J Vit Nutr Res 62, 312-317.

Rietveld A \& Wiseman S (2003) Antioxidant effects of tea: evidence from human clinical trials. J Nutr 133, 3285-3292.

Riley SJ \& Stouffer GA (2003) The antioxidant vitamins and coronary heart disease: part II. Randomized clinical trials. Am J Med Sci 325, 15-19.

Rimm EB, Stampfer MJ, Ascherio A, Giovannucci E, Colditz GA \& Willett WC (1993) Vitamin E consumption and the risk of coronary heart disease in men. $N$ Engl J Med 328, 1450-1456.

Roberfroid MB (1999) Concepts in functional foods: the case of inulin and oligofructose. J Nutr 129, 1398S-1401S.
Robertson B, Engstad RE \& Jøensen JB (1994) $\beta$-Glucans as immunostimulants in fish. In Modulators of Fish Immune Responses, pp. 83-99 [JS Stolen and TC Fletcher, editors]. Fair Haven, NJ: SOS Publications.

Roebuck KA \& Finnegan A (1999) Regulation of intercellular adhesion molecule-1 (CD54) gene expression. J Leukoc Biol 66, 876-888.

Roller M, Rechkemmer G \& Watzl B (2004) Prebiotic inulin enriched with oligofructose in combination with the probiotics Lactobacillus rhamnosus and Bifidobacterium lactis modulates intestinal immune functions in rats. $J$ Nutr 134, 153-156.

Sanchez-Moreno C, Dashe JF, Scott T, Thaler D, Folstein MF \& Martin A (2004) Decreased levels of plasma vitamin C and increased concentrations of inflammatory and oxidative stress markers after stroke. Stroke 35, 163-168.

Sano J, Inami S, Seimiya K, Ohba T, Sakai S, Takano T \& Mizuno K (2004) Effects of green tea intake on the development of coronary artery disease. Circ J 68, 665-670.

Schabath MB, Grossman HB, Delclos GL, Hernandez LM, Day RS, Davis BR, Lerner SP, Spitz MR \& Wu X (2004) Dietary carotenoids and genetic instability modify bladder cancer risk. J Nutr 134, 3362-3369.

Schley PD \& Field CJ (2002) The immune-enhancing effects of dietary fibres and prebiotics. Br J Nutr 87, 221-230.

Schmitz S (2004) Untersuchungen zur immunmodulativen Wirkung von $\beta-1,3 / 1,6-G l u k a n e n$ bei Schweinen (Investigations on the immunomodulatary effect of $\beta-1,3 / 1,6$-glucan in pigs). Dissertation, Tierärztliche Hochschule Hannover.

Serafini M, Maiani G \& Ferro-Luzzi A (1998) Alcohol-free red wine enhances antioxidant capacity in humans. J Nutr $\mathbf{1 2 8}$, $1003-1007$

Singleton VL \& Rossi JA Jr (1965) Colorimetry of total phenolics with phosphomolybdic-phosphotungstic acid reagents. Am J Enol Viticult 16, 144-158.

Stampfer MJ, Hennekens CH, Manson JE, Colditz GA, Rosner B \& Willett WC (1993) Vitamin E consumption and the risk of coronary disease in women. $N$ Engl J Med 328, 1444-1449.

Trevisanato SI \& Kim Y-I (2000) Tea and health. Nutr Rev 58, 1-10. Upritchard JE, Schuurman CRWC, Wiersma A, Tijburg LBM, Coolen SAJ, Rijken PJ \& Wiseman SA (2003) Spread supplemented with moderate doses of vitamin $\mathrm{E}$ and carotenoids reduces lipid peroxidation in healthy, non smoking adults. Am J Clin Nutr 78, 985-992.

van den Heuvel EGHM, Muys T, Van Dokkum W \& Schaafsma G (1999) Oligofructose stimulates calcium absorption in adolescents. Am J Clin Nutr 69, 544-548.

van den Heuvel EGHM, Schaafsma G, Muys T \& Van Dokkum W (1998) Nondigestible oligosaccharides do not interfere with calcium and nonheme-iron absorption in young, healthy men. Am J Clin Nutr 67, 445-451.

van Loo J, Cummings J, Delzenne N, et al. (1999) Functional food properties of non-digestible oligosaccharides: a consensus report from the ENDO project (DCXII AIRII-CT94-1095). Br J Nutr 81, 121-132.

Virtamo J, Rapola JM, Ripatti S, Heinonen OP, Taylor PR, Albanes D \& Huttunen JK (1998) Effect of vitamin E and beta carotene on the incidence of primary nonfatal myocardial infarction and fatal coronary heart disease. Arch Intern Med 158, 668-675.

Weinstein SJ, Wright ME, Pietinen P, King I, Tan C, Taylor PR, Virtamo J \& Albanes D (2005) Serum alpha-tocopherol and gamma-tocopherol in relation to prostate cancer risk in a prospective study. J Natl Cancer Inst 97, 396-399.

Weisburger JH (1998) Evaluation of the evidence on the role of tomato products in disease prevention. Proc Soc Exp Biol Med 218, 140-143. 